\title{
EL MUNDO CLÁSICO EN LAS PRIMERAS ÓPERAS DE WOLFGANG AMADEUS MOZART
}

\author{
José María Pérez Martel \\ IES Tomás de Iriarte (Santa Cruz de Tenerife) \\ jpermarm@gmail.com
}

\section{RESUMEN}

Este artículo analiza el tratamiento del mundo clásico grecorromano en la opera seria del siglo XVIII, cuyas convenciones dramáticas estableció el poeta italiano Pietro Metastasio. También examina el modo en que personajes y temas de la historia, literatura y mitología de Grecia y Roma son tratados en los libretos de las primeras óperas y serenatas teatrales del compositor austriaco Wolfgang Amadeus Mozart.

Palabras Clave: Metastasio, opera seria, tradición clásica, Mozart, Apollo et Hyacinthus, Mitridate re di Ponto, Ascanio in Alba, Il sogno di Scipione.

\section{ABSTRACT}

«The Classical World in the First Operas of Wolfgang Amadeus Mozart». This paper is an analysis of the treatment of the classical Greco-Roman world in the opera seria of the $18^{\text {th }}$ century, whose dramatic conventions were established by the Italian poet Pietro Metastasio. It also examines the way in which characters and themes from the history, literature and mythology of Greece and Rome are dealt in the librettos of the first operas and theatrical serenades of the Austrian composer Wolfgang Amadeus Mozart.

KeY wORDS: Metastasio, opera seria, classical tradition, Mozart, Apollo et Hyacinthus, Mitridate re di Ponto, Ascanio in Alba, Il sogno di Scipione.

Con esta breve colaboración nos queremos sumar al homenaje que la revista Fortunatae ofrece a la profesora García Gálvez. Con ella cursé asignaturas relacionadas con el griego bizantino y moderno, una de sus especialidades; posteriormente formó parte del tribunal calificador de mi Tesis Doctoral y, a partir de entonces, sus observaciones me animaron a seguir analizando las técnicas exegéticas y el léxico de la hermenéutica en los textos escolares, gramáticas y escolios bizantinos de los poetas trágicos griegos. En los últimos años, conté con su presencia como ponente en las Jornadas Colombinas que organizábamos en la isla de La Gomera, y a las que acudió con sumo grado. Destacaría de ella su enorme capacidad de trabajo, la meticulosidad y exquisitez de sus clases y escritos y, especialmente, su gran amor por la civilización griega de todas las épocas. 


\section{EL MUNDO CLÁSICO EN LA ÓPERA DEL SIGLO XVIII}

En la primera mitad del siglo XVIII la ópera mítica italiana del siglo anterior evolucionó a la denominada opera seria, que seguirá poniendo en escena en toda Europa pasiones y conflictos humanos representados por héroes míticos grecorromanos y, en menor medida, por personajes de la historia de Grecia y Roma junto con otros pertenecientes al antiguo Egipto, el fabuloso Oriente, el Antiguo Testamento y héroes de las Cruzadas. Conforme a las convenciones dramáticas del género, los protagonistas suelen ser dos parejas de amantes, casi todas suelen contener la figura del tirano magnánimo, ceremonias solemnes, ejemplos de valor, clemencia, sabiduría, prudencia y fidelidad bajo la apariencia de grandes gobernantes y conquistadores (Alejandro Magno, Artajerjes, Coriolano, Ulises, Escipión, o Tito), y siempre se resuelve la acción dramática por algún acto de heroísmo o de renuncia por parte de alguno de los protagonistas (Lapeña Marchena, 2004: 203). La voz de los castrati o castrados marcaba el componente mítico e irreal de esos personajes. Se componía para la corte, para un público culto con ocasión de bautizos, bodas, embajadas, y los libretos estaban llenos de alusiones a altos personajes (Jay Grout, 1984: 511).

Los preceptos dramáticos de este género teatral fueron establecidos por el poeta italiano Pietro Metastasio (Roma 1698-Viena 1782) a comienzos del siglo XVIII, el cual, además, utilizó como fuente de inspiración para sus libretos una enorme cantidad de personajes de la Antigüedad clásica, tanto míticos como históricos. Recibió una formación en la que las lenguas clásicas tenían un gran protagonismo, llegando a traducir La Ilíada a la edad de doce años. Dedicó la mayor parte de sus esfuerzos a la redacción de dramas para música [dramma per musica], género literario que evolucionaría rápidamente a los textos de la opera seria. También escribió poesía celebrativa en su oficio de poeta en la corte imperial de Viena y obras de teoría literaria. Su fama como libretista se extendió muy pronto por toda Europa, pues Metastasio superó en calidad y elegancia todas las muestras anteriores en el campo de los libretos operísticos. Los títulos de sus libretos, musicados por los grandes compositores europeos del siglo XVIII (Johann Hasse, George F. Handel, Antonio Vivaldi, Wolfgang A. Mozart, Alessandro Scarlatti, Ch. W. Gluck...), nos dan idea de la presencia del mundo clásico grecolatino en sus producción dramática: Gli Orti Esperidi, Catone in Utica, Didone abbandonata, Demofoonte, Olimpiade, Achille in Sciro, Ipermestra, Clemenza di Tito, etc.

Metastasio estudia las fuentes que utiliza para componer sus libretos, las cita con frecuencia, y, además, se interesa por la teoría literaria clásica. Entre sus títulos destacan especialmente los relacionados con la Historia de Roma. En estos libretos operísticos, el poeta italiano reinterpreta la romanidad haciendo una lectura alegórica y política de la misma, y entendiéndola como una suma de heroísmo, virtud y patriotismo. En sus obras las virtudes romanas se basan en el respeto a las leyes y la identificación de un valor patriótico y civil que está por encima de la vida del individuo (Martín Puente, 2013: 190).

Gracias a la llegada a España en 1737 del castrado Farinelli, sobrenombre del célebre cantante italiano Carlo Broschi, las obras de Metastasio se conocieron en nuestro país, pues casi todas las óperas que cantó el virtuoso cantante eran traducciones al español de textos del libretista italiano. Alcanzaron tal éxito entre los drama- 
turgos y compositores que contribuyeron a renovar el teatro español del siglo XVIII (Martín Puente, 2013: 190, 194). Algunos títulos de Metastasio, adaptados y denominados dramma harmónico o melodramma scenico por los dramaturgos españoles, son Trajano en Dacia, y cumplir con amor y honor (1735), texto de José de Cañizares y música de Francesco Corradini; Por amor y por lealtad recobrar la majestad, y Demetrio en Siria, (1736), texto de Vicente Camacho según Demetrio de Metastasio de 1731, música de Giovanni Battista Mele; Más gloria es triunfar de sí, Adriano en Syria (1737), según Adriano en Siria de Metastasio de 1737, con música de José de Nebra; Amor, constancia y mujer (1737), según Siface re di Numidia de Metastasio de 1723, música de Giovanni Battista Mele (Pérez Martel, 2017: 593-594).

Queremos atraer la atención sobre un intermedio que el poeta italiano estrenó en 1724 y que tiene como protagonista a un personaje natural de las Islas Canarias. Se trata de L'impresario delle Isole Canarie. Lleva el subtítulo de Intermezzo per la Didone [Didone abbandonata] y narra las peripecias de un empresario que viajaba desde las Islas Canarias a Italia en busca de la cantante principal para su compañía de ópera. La elección de nuestras islas como origen del empresario musical parece obedecer al gusto por lo exótico y lejano de la literatura y música del siglo XVIII (Neville, 2001: 518). Durante este siglo, célebres compositores italianos escribieron música para este desconocido texto metastasiano, como es el caso de Tommaso Albinoni (1671-1750) y Giovanni Battista Martini (1706-1750).

Hasta finales del siglo XVIII la opera seria será el más autorizado y acreditado espectáculo musical, y en todo teatro que se precie, cada temporada musical se inicia con una de estas óperas. El género se seguirá cultivando conservando la tradición del barroco musical italiano. Los mejores representantes de este género a finales del XVIII son N. Jommelli (1714-1774) y, muy especialmente, T. Traetta (1727-1779). Y es en este género musical en el que Mozart escribió música para algunas de sus primeras composiciones para el teatro y para sus óperas.

La preeminencia de la mitología clásica en la escena musical europea comenzó a decaer a finales del siglo XVIII, después de casi dos siglos de exclusividad, debido al avance del pensamiento esclarecido de fines de ese siglo, y a que los gustos del público, constituido en su mayor parte por la nobleza, iban cambiando y preferían temas más ligeros, frívolos y de carácter afable, incluso cómicos. Con la entrada del Romanticismo, los temas míticos e históricos del mundo clásico, descienden de su posición privilegiada como materia principal para los libretos operísticos, aunque siguen siendo tratados débilmente y con nuevos enfoques. La ópera romántica orienta sus argumentos hacia los temas históricos, la exaltación de las relaciones sentimentales y la elevación del mundo íntimo.

\section{MOZART Y EL MUNDO CLÁSICO}

La instrucción y formación, al igual que la educación musical, recibida por Mozart en sus primeros años se debe a su padre Leopold, hombre culto, violinista y maestro de capilla de la corte del príncipe arzobispo de Salzburgo. Muy pronto entiende su padre que las cualidades prodigiosas de su hijo deben ser conocidas en 
toda Europa, y por ello emprende varios viajes buscando algún puesto de trabajo adecuado para él y sus hijos. En estos viajes de infancia, la instrucción que va recibiendo Mozart de su padre fue ocasional y muy escasa. Suponemos que tuvo que estar en contacto, desde muy pronto, con los siguientes lenguas: el latín, para la música sacra, principalmente, los textos del Ordinarium Missae y Letanniae, el griego, para los kyries de sus misas y los comienzos de las letanías; el hebreo del amén, alleluya y hosanna; el italiano, idioma aprendido pronto y rápidamente, para la mayoría de sus óperas y arias; y, naturalmente, el alemán, idioma de su país natal, para los Singspiel. Casi todos los textos latinos de las composiciones mozartianas están en latín eclesiástico-litúrgico medieval. Nada de latín clásico. Un título: El Galimathias musicum (K. 31) es solo el título de una serenata quodlibet (popurrí) para clavicordio y orquesta (Quirós Rodríguez, 2006: 135).

Los temas del mundo clásico, en especial los de contenido mítico, literario, y los relacionados con la historia de Roma y sus personajes, sí estuvieron desde su juventud muy presentes en su vida. De las veintidós óperas y composiciones teatrales de Mozart, ocho tienen como argumento temas del mundo clásico, y de ellas tres son de contenido exclusivamente mitológico: Apollo et Hyacinthus seu Hyacinthi Metamorphosis. Comoedia Latina (KV 38), Ascanio in Alba (KV 111) y Idomeneo, re di Creta ossia Ilia e Idamante (KV 366). Las otras cinco contienen temas históricos y literarios de Grecia y Roma: Mitridate, re di Ponto (KV 87), Il sogno di Scipione (KV 126), Lucio Silla (KV 135), Il re pastore (KV 208) y La clemenza di Tito (KV 621). En esta colaboración centraremos nuestra atención en los libretos de las cuatro primeras composiciones del músico austriaco relacionadas con el mundo clásico.

\subsection{Apollo et HyaCinthus SEU HyaCinthi METAMorphosis. COMOEDIA LATINA (KV 38)}

A la edad de once años la Universidad de Salzburgo encargó al joven Mozart componer la música para un intermedio cómico escrito por el monje benedictino Rufinus Wild (1731-1798). Este religioso, profesor de Filosofía y Sintaxis en la citada Universidad, había escrito también una tragedia en latín en cinco actos, Clementia Croesi, para representar al final del curso 1767, tradición que se venía haciendo en el Gran Hall de la Universidad desde 1617, siempre con dramas que tuviesen argumentos tomados de la cultura clásica grecolatina. El tema de la tragedia procedía de Heródoto I, 34-35, y es el célebre episodio de Creso, rey de Lidia, y el frigio Adrasto: Creso manda a Adrasto que cuide de su hijo Atis durante una cacería, pero lo mata de forma accidental. Creso, consumido por la angustia y la furia, finalmente le perdona pues piensa que ha sido la divinidad quien lo ha matado, tal y como un sueño profético le había vaticinado. Es ese perdón el que da título a la obra y argumento a los cinco actos del drama de Rufinus Wild. Pues bien, era costumbre que entre los actos de la tragedia representada, se interpretase un corto intermedio musical, escrito en latín, que sirviese de refuerzo y complemento del mensaje y contenido didáctico de la obra principal. 
El intermedio cómico del padre Widl cuenta el mito clásico de Apolo y Jacinto, y la muerte accidental de este último causada por el disco lanzado por el dios. En cuanto a las fuentes usadas, no se indican, si bien podemos pensar que acudió a las originales: Eurípides, Helena 1469; Apolodoro, Biblioteca I, 3, 3 y III, 10, 3; Ovidio, Metamorfosis X, 162-219; y Pausanias, Descripción de Grecia III, 19, 5. El segundo amante de Jacinto en la obra del padre Wild aparece como un añadido a partir de Luciano en Diálogos de los dioses, XIV. Se trata de Céfiro, mientras que en Servio, Églogas, III, 63 y Apostolio XXI, 19 era Bóreas. Tampoco se descarta que acudiese el padre Widl a los repertorios, léxicos y diccionarios mitológicos más usuales en la época, especialmente los de Benjamin Hederich (1724) y Johann H. Zedler (1753).

La historia que crea el padre Widl a partir del mito clásico presenta algunos cambios sustanciales que no se encuentran en las fuentes clásicas. Seguimos algunas de las consideraciones de Ruiz de Elvira (1992: 33-34):

1. Añade dos personajes nuevos: Melia, hermana de Jacinto y objeto de amor de Apolo y Céfiro, y el padre de ambos, Oebalus, rey de Lacedemonia. La consecuencia de añadir nuevos personajes es bien clara: el triángulo amoroso homosexual entre Apolo, Jacinto y Céfiro, se transforma en heterosexual siendo ahora Melia la amada por Apolo y Céfiro. Eso estaba más en consonancia con la moral católica del padre Wild y con las modas y gustos de la audiencia del siglo XVIII. No obstante, ese amor homosexual no se diluye del todo y está latente, creemos, en diversos momentos de la obra, como en el primer recitativo del acto I, cuando Céfiro ofrece su corazón a Jacinto y le dice:

O care! Quam libenter offerem ilia pectusque

Si tu Apollo meus fores

De igual forma en el recitativo previo al aria n. ${ }^{\circ} 3$, es Apolo quien ofrece su verdadera 'amistad' a Jacinto:

Hyacinthe! Amicum semper addictum tibi habebis

In me, amare si Deum potes

Asimismo, cuando Céfiro acusa al dios Apolo de la muerte de Jacinto y escucha a Amelia decir que ya no se casará con el dios, Céfiro, lleno de odio hacia el dios, no permitirá que le quite también a su querida, igual que hizo anteriormente con Jacinto (recitativo previo al aria n. ${ }^{\circ}$ ):

Quid audio? An coniugia meditatur Deus?

An Meliam et rapuisse mihi amatam cupit?

Qui rapuit Hyacinthi, anne et istius mihi rapiet amorem?

Finalmente, en el recitativo $\mathrm{n} .{ }^{\circ} 1$ del acto III, cuando Jacinto ya moribundo desvela quién es su verdadero asesino, solo desea entonces que el dios Apolo esté junto a él:

Zephyrus...heu me!...si...Deus adesset!... 
2. La calumnia de Céfiro, que acusa al dios Apolo de la muerte de Jacinto.

3. El destierro de Apolo de las tierras de Lacedemonia tras ser acusado de asesinato y la promesa de Apolo de casarse con Melia.

Es tal el protagonismo de Céfiro en la obra que pensamos que es él, y no Apolo o Jacinto, el principal personaje del texto. Está presente en casi todos los recitativos. Desde el mismo comienzo, Céfiro es presentado como un ser celoso, enamorado de Melia desde hace tiempo sin ser correspondido e incapaz de soportar sus desprecios. Maquina e interviene en el desenlace fatal del lanzamiento de disco que ocasionará el destierro de Apolo, un ser orgulloso que no acepta el rechazo de Melia a su amor, un ser sumamente cobarde que no es capaz de anunciar el destierro a Apolo por miedo a sus represalias y que se esconde, cuando este regresa, para declarar su inocencia por miedo a su furor. Este carácter mezquino y aborrecible es el mismo que describe Luciano en el diálogo entre Hermes y Apolo citado anteriormente en las fuentes, y que bien pudiera haber conocido el padre Widl.

La relación amorosa entre Apolo y Jacinto no tuvo mucha fortuna en el terreno musical, hecho que no se constata con otro amor célebre del dios como lo fue Dafne, con más de veinte composiciones musicales, destacando en este caso las óperas de J. Peri, H. Schütz, P. F. Cavalli, J. B. Lully, G. F. Händel, A. Caldara, A. Bird o R. Strauss (Harrauer Ch. y Hunger H., 2008: 205). De los amores de Apolo y Jacinto solo contamos con la cantata de J. S. Bach BWV 201 que lleva por título Geschwinde, ihr wirbelnden Winde (Der Streit zwischen Phoebus und Pan). El autor del texto, publicado en 1732, fue Christian Friedrich Henrici (1700-1764), poeta y libretista alemán, y tiene su fuente en las Metamorfosis de Ovidio, XI, 146-193. La otra obra que trata los amores de Apolo y Jacinto es la cantata de cámara Apolo y Jacinto, estrenada en el año 1948, de Hans Werner Henze (1926) con texto del poeta austriaco Georg Trakl (1887-1914).

\subsection{Mitridate, RE DI PONTO (KV 87)}

Es la primera opera seria de Mozart, compuesta con catorce años y basada en la traducción del poeta italiano Giuseppe Parini (1729-1799) de la tragedia Mithridate (1673) del dramaturgo francés Jean-Baptiste Racine (1639-1699). Vittorio Amadeo Cigna-Santi (1725-1783), libretista y poeta, versificó la traducción de Parini para la ópera de Mozart. Este poeta residía en Turín y envió a Milán el libreto por partes en diversas entregas, a las que Mozart fue escribiendo música. Se estrenó de forma brillante en el Teatro Regio Ducale de Milán el veintiséis de diciembre de 1770 .

El protagonista de la ópera es Mitrídates VI Eupator, (132-63 a.C.), rey del Ponto desde el año 120 a.C. hasta su muerte, e hijo de Mitrídates v Evergetes (150-120 a.C.). Esta figura histórica, gran adversario de los romanos en oriente, aparece en diversas fuentes clásicas como Dión Casio, y las biografías de Plutarco sobre Sila, Pompeyo, y Lúculo, contra quienes combatió repetidamente en las denominadas Guerras Mitridáticas, según relata Apiano en su Historia Romana, XII, De bello Mithridatico. Es conocido tanto por la leyenda de su resistencia a todo tipo 
de veneno, gracias a un antídoto que él mismo creó y fue llamado posteriormente mitridato (Dión Casio, Historia romana XXXVII 13, Aulio Cornelio Celso, De Medicina 23.3), como por el hecho de ser un obstinado rey obsesionado con frenar el poder de Roma en oriente que no era entonces frenado por ningún obstáculo. Incluso proyecta al final de su vida invadir Italia, proyecto que no pudo ejecutar pues se suicida al ser traicionado por su hijo.

La figura que esbozó Jean Racine (Moormann y Uitterhoeve, 1998: 190 y ss.) del monarca se centra exclusivamente en dos aspectos: a) lo considera el último baluarte contra el poderío de los romanos a los que profesa un gran odio y b) ese odio hacia el poderío romano está unido durante toda la tragedia a múltiples aspectos de tipo familiar y de intrigas amorosas, muy del gusto de la época: el rey del Ponto sospecha que sus hijos le quieren usurpar el poder en su reino y el amor de su prometida Aspasia. Por ello finge su muerte en un combate lejano para conocer la reacción de sus hijos Farnace, fiel al adversario romano y enamorado de la prometida de su padre, y Sifare, simpatizante de los griegos y pretendiente también de Aspasia. Cuando aparece Mitrídates acompañado por la princesa Ismene para casarla con su hijo Farnace y conseguir así una alianza con el Imperio parto, y conoce la traición de Farnace y el amor que sienten sus dos hijos por su prometida, los condena a muerte. La princesa clama a la clemencia del monarca, tema recurrente en la ópera seria del siglo XVIII, como hemos indicado antes, para que perdone a sus hijos. No lo consigue. Es entones cuando el tribuno romano Marcio, aliado de Farnace que se ha presentado en Ninfea con tropas para acabar con Mitrídates, lo libera. Farnace recapacita y decide ayudar a su padre, que ya se ha suicidado ante la presumible derrota ante los romanos, y es justo antes de morir cuando el monarca conoce que han vencido a los romanos gracias a su hijo Farnace. La obra acaba con un canto a la libertad de los pueblos y a la lucha armada contra el poder opresor del Imperio Romano.

Antes de Racine, la historia de Mitrídates VI Eupator ya había sido puesto por escrito en las tragedias de La Calprènede (1635) y Lee (1678). En el terreno musical, el tema de Mitrídates atrajo el interés de diversos compositores y libretistas célebres como A. Scarlatti y M. Norris (1701), A. Scarlatti y G. Frigimelica Roberti (1707), N. Porpora y F. Vanstryp (1730), N. Porpora y G. Gavardo (1736), y D. Tarradellas y F. Vaneschi (1746).

\subsection{ASCANIO IN ALBA (KV 111)}

Esta composición, denominada serenata teatrale, fue compuesta por Mozart a la edad de quince años por encargo real de la emperatriz María Teresa de Austria, para ser interpretada con ocasión de la boda de su hijo el archiduque Fernando (17541806) con María Beatrice d'Este (1750-1829), única hija del príncipe de Módena. Se estrenó en el Teatro Regio Ducal de Milán el 17 de octubre de 1771. El autor del libreto es nuevamente el poeta y traductor italiano Giuseppe Parini. Actualmente es una de las obras musicales de Mozart menos representada y consta de numerosos recitativos, coros y ballets. 
El libreto centra su argumento, con la excusa de la fundación de la ciudad de Alba Longa por orden de Venus, en la prueba que somete Ascanio, el hijo de Venus y Eneas en el texto de Parini, a su futura esposa Silvia, de la estirpe de Hércules, para comprobar sus virtudes antes de la boda. La diosa Venus, que simboliza a la emperatriz María Teresa, le dice a su hijo Ascanio, que representa al Archiduque Fernando, que se convertirá en rey de Alba y tomará como esposa a Silvia, que simboliza a la princesa María Beatrice, futura esposa del archiduque. Desde hace cuatro años, Cupido ha tomado la apariencia de Ascanio, a quien Silvia nunca ha conocido, y se le presenta en sueños desde entonces. La joven confiesa al sacerdote de Venus, su dilema: siente un gran amor por el ser que ve en sueños y una gran admiración por el ser virtuoso del que todos hablan y con el que contraerá matrimonio. El sacerdote le indica que los dos seres son la misma persona, su futuro esposo Ascanio. Pero cuando todo parece acabar bien, la diosa Venus propone otra prueba para comprobar la virtud y fidelidad de Silvia haciendo que los novios se separen un tiempo. Es en ese momento cuando se inicia la construcción de la ciudad de Alba mediante la transformación de árboles de la zona en columnas de templos y bellos edificios. La obra finaliza cuando, después de mucho tormento y desesperación por parte de los futuros esposos que desean verse, la diosa aparece en escena y presenta a los prometidos, encomendado al futuro esposo el diseño y construcción de Alba Longa y la administración de justicia en la toda la región.

El libretista Parini introduce cambios en la historia mítica: la madre de Ascanio no es Creúsa, princesa troyana hija de Príamo y Hécuba, sino la diosa Venus, madre de su padre Eneas. Este cambio se entiende al representar la diosa a la emperatriz María Teresa de Austria (Brown, P. 2006: 26). Por otro lado, aparecen personajes nuevos ausentes en las fuentes clásicas (fundamentalmente Virgilio, Eneida, especialmente VII, 483-492, y Livio I, 3, 3). Esos nuevos protagonistas de la trama son el pastor Fauno, que interpreta para Ascanio el significado de algunos acontecimientos que van sucediendo; el sacerdote de Venus, Acestes, que guía y protege a Silvia en toda la serenata según le indica la diosa al inicio de la misma; y, finalmente, diversos Genios y Gracias como habitantes de la aldea que se convertirá en la futura ciudad de Alba Longa al final de la obra. Por otro lado, Ascanio se ve obligado a fundar la ciudad de Alba Longa cuando tiene que huir de entre los latinos porque estos tomaron partido por su madrastra Lavinia (Dionisio de Halicarnaso, Antigüedades romanas, I, 66). La fundó en el lugar en el que su padre Eneas había sacrificado una jabalina blanca y sus treinta lechones. Parini introduce la construcción de la ciudad al final del primer acto, tras proponer una prueba para comprobar la virtud de Silvia.

El tema de Ascanio y la fundación de Alba Longa no tuvo mucha fortuna en el terreno musical anterior ni posterior a Mozart. En 1686 se estrenó la ópera Ascanio in Alba con música de G. A. Bernabei y libreto de V. Terzago; en 1786 la ópera con el mismo título de A. L. Moreira y libreto de C. N. Stampa, y en 1890 el Ascanio de C. Saint-Saëns con libreto de L. Gallet.

\subsection{IL SOGNO DI SCIPIONE (KV 126)}

El argumento del Somnium Scipionis de Cicerón, presente en De re publica, libro VI 9-29, constituía un argumento idóneo para una composición en forma de 
homenaje. Así lo hizo Pietro Metastasio en 1735 en forma de serenata drammatica para la coronación del emperador Carlos VI (1685-1740). A Mozart se le encargó la composición de la música para el texto metastasiano como homenaje al príncipearzobispo de Salzburgo Siegmund Christof von Schrattenbach (1698-1771). Pero tras la repentina muerte del príncipe, se la dedicó a su sucesor, Hieronymus von Colloredo (1732-1812), soberano y posterior patrón de Leopold Mozart y su hijo Wolfgang. Se estrenó en el Palacio del príncipe-arzobispo de Salzburgo el uno de mayo de 1772 .

Al libreto de Metastasio ya le habían puesto música otros compositores de la época, como J. A. Hasse (1699-1783), G. Sarti (1729-1802), Ch. W. Gluck (17141787), N. Jommelli (1741-1790), N. Piccinni (1728-1800) y B. Galuppi (1706-1785).

En el diálogo De re publica ciceroniano diversos personajes relevantes de la vida política romana se reúnen para conversar sobre los sistemas de gobierno en una finca de recreo de Escipión Emiliano durante los tres días en que se celebraron las feriae latinae del 129 a. C. El tema principal de las conversaciones es la superioridad de la vida política activa frente a la teorética, y el premio que en la otra vida tendrán los que se hayan esforzado notablemente por defender a su patria. De la obra solo conservamos un manuscrito descubierto en 1819 por el cardenal Angelo Mai en los fondos de la abadía de San Columbano, en Bobbio, Italia. El texto ciceroniano estaba oculto bajo unos comentarios de los Salmos de San Agustín. Se trata del palimpsesto Vat. Lat. 5757. Sin embargo, este manuscrito contiene escasos fragmentos de los libros I, II y III, mientras que de los tres últimos apenas contiene nada. Por ello es de gran importancia el testimonio de otros autores. Los más importantes son Nonio Marcelo, San Agustín, Lactancio y Macrobio (D’Ors, 1984: 11).

Como broche final para su diálogo, Cicerón compuso el Sueño, a imitación del mito de Er con el que Platón finalizaba su República. El texto posee diversas influencias: desde Posidonio y Platón, especialmente por la descripción astronómica y la formación cósmica de las almas (Timeo, República), hasta doctrinas y creencias pitagóricas y neoplatónicas. El personaje principal es Publio Cornelio Escipión Emiliano Africano Numantino (185-129 a. C.) Venidos desde el más allá, aparecen Publio Cornelio Escipión Africano (235-183 a. C.), y Lucio Emilio Paulo Macedónico (228- 160 a. C.)

El argumento es el siguiente: Escipión Emiliano visita en África al rey Masinisa en el curso de la III Guerra Púnica, y durante un sueño se le aparece su abuelo Publio Escipión Africano. Le revela su destino futuro, el de su país, le explica las recompensas que aguardan a la virtud en la otra vida, y le describe el universo y el lugar de la Tierra y el hombre dentro del universo. En medio de la obra aparece también su padre Lucio Emilio Paulo. Por último, Publio Escipión le presenta el lugar del más allá donde se ha reservado un lugar al joven Escipión después de haber cumplido sus obligaciones con su familia y con su patria.

Esta conversación del clan los Escipiones gozó de gran popularidad en toda la Edad Media, gracias al comentario de Macrobio (comienzos del siglo v), que interpretó el texto de Cicerón en un sentido cristiano. Macrobio no ofrece un comentario exhaustivo del texto ciceroniano, sino que expone una serie de teorías sobre los sueños de corte neoplatónico, sobre las propiedades místicas de los números, sobre 
la naturaleza del alma, sobre astronomía y sobre música. Presenta posibles influencias de Plotino y Porfirio, autores a los que seguramente leyó, y cita con frecuencia a Virgilio como fuente de autoridad y como adorno estilístico (Navarro Antolín, 2006: 26).

Ecos literarios del Sueño son Roman de la Rose del siglo XIII, The House of Fame (1380) de Geoffrey Chaucer, y Numancia (1600) de Miguel de Cervantes. (Moormann y Uitterhoeve, 1998: 144).

Del cotejo de los textos ciceroniano y metastasiano consideramos que se pueden extraer las siguientes consideraciones:

1. Metastasio introduce dos personajes ajenos al texto ciceroniano: Fortuna y Constancia, que vienen a representar, respectivamente, la fama terrenal frente a la eternidad para los que viven en algún lugar del cielo y han luchado y cuidado su patria.

2. Frente al protagonismo de los dos Escipiones en el texto de Cicerón, en Metastasio Publio Cornelio presenta un papel muy secundario. En Cicerón acompaña al joven Escipión Emiliano durante todo el sueño hasta que despierta, informándole al comienzo del lugar dónde se encuentra, e interpretándole todo lo que va viendo. En Metastasio, en cambio, los verdaderos protagonistas de la obra, además de Escipión Emiliano, son Constancia, Fortuna y su padre Lucio Emilio Paulo. Su abuelo Publio Cornelio aparece en escena a mitad de la obra (recitativo tras el aria n. ${ }^{\circ} 4$ ), y se lo encuentra, casi por casualidad, para explicarle al joven Escipión que los cuerpos mueren, pero el espíritu es inmortal, que todos los que dedican su vida al bien público y vierten su sangre para beneficio de los demás, tendrán recompensa tras la muerte del cuerpo observando el cielo y el armonioso movimiento de sus elementos. Más adelante le indicará que la decisión de elegir entre la Constancia y la Fortuna debe tomarla él solo, sin ayuda de ninguno de sus familiares (recitativo tras el aria n. ${ }^{\circ} 7$ ).

3. Las referencias astronómicas y geográficas, tan desarrolladas en Cicerón por parte de Publio Cornelio (VI 14-22), apenas tienen presencia en Metastasio, y se limitan a breves indicaciones, ofrecidas en este caso por su padre Emilio, sobre el sonido y movimiento de la esferas celestas, y la forma y posición de la Tierra (breve recitativo tras el aria n. ${ }^{\circ}$ 5).

4. El final de las dos obras es también diferente. En ambas Escipión ha tomado ya una decisión: en Cicerón, esforzarse en vida y salvar la patria para obtener el premio eterno de la contemplación del universo. Tras esa decisión, despierta plácidamente recordando lo soñado (VI 26). En Metastasio, tras optar por Constancia y declararle Fortuna que será su eterna enemiga, se inicia una fuerte tempestad de la que despierta bruscamente recordando también lo soñado, convencido de que la visión de Constancia no fue un sueño, y aceptando la voluntad de los dioses (recitativo tras el aria n. ${ }^{\circ} 10$ ). Tras esto, se inicia la cantata-homenaje para la investidura del príncipe-arzobispo Colloredo, en cuyos primeros versos del recitativo, el autor del texto, que ya no es Metastasio, explica que el verdadero Escipión de la azione teatrale representada es el arzobispo de Salzburgo. 


\section{REFERENCIAS BIBLIOGRÁFICAS}

Brown, P. (2006): "Ascanio in Alba” en EISEn, C. y KeEFE, S. P., The Cambridge Mozart Encyclopedia, pp. 25-27.

CICERÓN (1984): Sobre la República, introducción, traducción, apéndice y notas de Á. D’Ors, B. C. Gredos, Madrid.

Del Corno, D. (1994): "La classicità greco-latina nel teatro di Mozart", Kleos 1: 77-82.

Faravelli, D. (1994): “Cicerone, Metastasio, Mozart: il Sogno di Scipione”, Zetesis 2. $<$ http://www.rivistazetesis.it/Mozartsognoscipione.htm> [Acceso julio 2017].

Ferri-BenedetTI, F. (2012): "El legado de la tradición clásica. El caso de la ópera barroca” Florentia iliberritana: Revista de estudios de antigüedad clásica 23: 45-62.

Grout, D. J (1984): Historia de la música occidental, 2, Madrid.

Harrauer, Ch. \& Hunger, H. (2008): Diccionario de mitología griega y romana, Barcelona.

Lapeña Marchena, Ó. (2004): "La imagen del mundo antiguo en la ópera y en el cine. Continuidad y divergencia”, Veleia 21: 201-215

Lederer, Th. (2009): "The clemency of Rufinus Widl. Text and and context of W. A. Mozart's first opera”, en Humanistica Iovaniensia: Journal of Neolatin Studies 58: 217-373.

Martín Puente, C. (2013): "Las obras sobre la Historia de Roma de Metastasio y sus traductores al español con especial atención al jesuita Benito Antonio de Céspedes", Cuadernos de investigación filológica 39: 187-204.

MCDonald, M. (2002): "Canta la tua pena. I classici, la storia e le eroine nell'opera", Kleos 6: 9-445.

Macrobio (2006): Comentario al «Sueño de Escipión» de Cicerón, introducción, traducción y notas de F. Navarro Antolín, B. C. Gredos, Madrid.

Moormann, E. M. \& Uitterhoeve W. (1998): De Adriano a Zenobia. Temas de la historia clásica en la literatura, la música, las artes plásticas y el teatro, Madrid.

Neville, D. (2001): "Metastasio, Pietro», en The New Grove Dictionary of Music and Musicians, Londres, XVI, pp. 510-519.

Pérez Martel, J. Ma (2007): "Sófocles en la música”, en Actas del Congreso Canariense sobre el teatro de Sófocles, Madrid, pp. 265-270.

— (2017) "Zarzuela barroca y mito clásico: Iphigenia en Tracia de Nicolás González Martínez

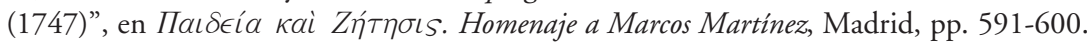

Quirós Rodríguez, M. A. (2006): "Literatura sacra en la música sacra de W. A. Mozart (el latín, el griego y el hebreo en su música)", Káñina XXX (1): 133-154.

Ruíz de Elvira Prieto, A. (1992): “Jacinto”, Myrtia 7: 7-40.

SAVOIA, F. (2000): "Parini librettista: Ascanio in Alba", La Rassegna della letteratura italiana 104 (2): $388-419$.

Seguí Marco, J. J. (2011): “El sueño evanescente de Cicerón: el paraíso de los políticos”, Potestas 4: 55-68. 
